\title{
A Peculiar Case of Priapism: The Hypercoagulable State in Patients with Severe COVID-19 Infection
}

\author{
Germain Lam, Rowan McCarthy, Rana Haider \\ General Internal Medicine, Withybush General Hospital, Haverfordwest, Pembrokeshire, United Kingdom
}

Doi: 10.12890/2020_001779 - European Journal of Case Reports in Internal Medicine - C EFIM 2020

Received: 06/06/2020

Accepted: 09/06/2020

Published: $14 / 07 / 2020$

How to cite this article: Lam G, McCarthy R, Haider R. A peculiar case of priapism: the hypercoagulable state in patients with severe COVID-19 infection. EJCRIM 2020;7: doi:10.12890/2020_001779.

Conflicts of Interests: The Authors declare that there are no competing interests.

Acknowledgements: The Authors would like to thank the patient's partner for allowing us to write and publish this case report. We would also like to thank Dr Verona Mihai who was the patient's primary consultant.

This article is licensed under a Commons Attribution Non-Commercial 4.0 License

\section{ABSTRACT}

It is increasingly recognised that patients with severe COVID-19 infection have a significant risk of thromboembolic events. We describe a patient who rapidly deteriorated due to severe infection with COVID-19, and developed priapism in the last days of his life. We believe development of priapism may be associated with a prothrombotic state secondary to COVID-19 infection. This case report supports the widely reported increased incidence of thrombosis in patients with severe COVID-19 infection.

\section{LEARNING POINTS}

- Prophylactic doses of anticoagulation may not be sufficient in patients with severe COVID-19 infection, but clinical trials of therapeutic dose anticoagulation are underway.

- Physicians should be vigilant and have a high suspicion for thrombosis in all patients with COVID-19 infection, even those who are anticoagulated.

- Presentations of thromboembolism and microemboli may be atypical.

\section{KEYWORDS}

Priapism, thromboembolism, coagulopathy, COVID-19 infection, anticoagulation

\section{INTRODUCTION}

The arrival of the novel coronavirus disease COVID-19 has caused a global pandemic affecting more than a million people ${ }^{[1,2]}$. While the symptomatology of the disease varies greatly between individuals, it can cause critical illness and severe respiratory failure ${ }^{[3]}$. The variety of complications associated with this novel pathogen are being recognised. One such complication is an increased risk of thrombotic and thromboembolic disease in patients with severe COVID-19 infection ${ }^{[1-7]}$, even those who are anticoagulated ${ }^{[3]}$. The high incidence of thrombotic complications seen in COVID-19 infection is thought to be due to the direct effect of the pathogen on the coagulation system [1,3-6], and indirectly via mechanisms such as critical illness, severe inflammatory response and immobility ${ }^{[3-6]}$.

\section{CASE DESCRIPTION}

We treated a 67-year-old man who developed severe COVID-19 infection. He unexpectedly developed priapism in the last days of his life. Given the rarity of priapism ${ }^{[8]}$ and the increased incidence of thromboembolic events and microemboli formation observed in patients with severe COVID-19 infection ${ }^{[1-7]}$, we hypothesise that this patient may have developed priapism due to a prothrombotic state associated with COVID-19 infection. 
The patient presented on 30 March 2020 with a 2-week history of pyrexia, myalgia, cough and breathlessness. His co-morbid conditions included dilated cardiomyopathy of unknown aetiology, cutaneous scleroderma, paroxysmal atrial fibrillation (anticoagulated with warfarin), type 2 diabetes mellitus, and iron deficiency anaemia.

On admission the patient was hypoxemic $\left(\mathrm{SpO}_{2} 85 \%\right.$ (FiO2 21\%), respiratory rate 28 breaths/min), and haemodynamically compromised (blood pressure 86/51 mmHg; heart rate 88). Admission blood results showed platelets 108, D-dimer 428, APTT 40.2, PT 27.1 and fibrinogen 7.0. A pharyngeal swab PCR test confirmed SARS-CoV-2 RNA. Electrocardiography revealed a sinus rhythm with left bundle branch block (chronic). Chest $x$-ray (CXR) showed extensive consolidation in the right hemi-thorax, and ground-glass opacification in the left mid and lower zones suggestive of COVID-19 pneumonia.

Treatment started on admission included supplemental oxygen, intravenous ceftriaxone, oral doxycycline and oral oseltamivir. Due to worsening hypoxia ( $\mathrm{SpO}_{2} 88 \%$ on 15 litres/min of oxygen), a trial of continuous positive airway pressure (CPAP) was commenced, which the patient found distressing. Despite treatment with CPAP and high flow nasal oxygen, the patient continued to deteriorate, and there was evidence of multi-organ failure. A repeat CXR showed four quadrant infiltrates in keeping with the development of acute respiratory distress syndrome. Subsequently, the patient developed minor penile bleeding and paraphimosis, which was reduced on two occasions. Following discussions with the patient, treatment focus was redirected to the management of his symptoms, and curative intervention ceased.

Of note, a few hours later he developed an exquisitely painful priapism with a dusky appearance and rigid corpora cavernosa, suggesting low-flow (ischaemic) priapism [8-10]. Other than possible minor trauma from reduction of the paraphimosis, there were no known risk factors for priapism; new medications that were started were not associated with priapism. The condition was managed conservatively due to his rapid clinical deterioration, based on urology advice. The patient died shortly afterwards.

\section{DISCUSSION}

Venous thromboembolism is increasingly recognised as a complication in patients diagnosed with COVID-19, especially those with severe disease ${ }^{[2-6]}$. We recognise that trauma from the manipulation of his paraphimosis may have played a role in the development of our patient's priapism, however given the rarity of this as a complication of paraphimosis, we hypothesise that coagulopathy and possible microemboli formation secondary to COVID-19 infection may have led to obstruction of draining venules, resulting in low-flow priapism ${ }^{[8-10]}$.

In conclusion, we believe this case may support the growing evidence of coagulopathy and thrombotic events associated with severe COVID-19 infection ${ }^{[1-7]}$. Further strategies are required to diagnose and prevent thrombotic disease in patients with COVID-19, keeping in mind the emerging evidence that prophylactic dose anticoagulation may not be sufficient in preventing thromboemolism in patients with severe infection ${ }^{[1-5]}$.

\section{REFERENCES}

1. Cannegieter SC, Klok FA. COVID-19 associated coagulopathy and thromboembolic disease: commentary on an interim expert guidance. Res Pract Thromb Haemost 2020;4(4):439-445.

2. Wang T, Chen R, Liu C, Liang W, Guan W, Tang R, et al. Attention should be paid to venous thromboembolism prophylaxis in the management of COVID-19. Lancet Haematol 2020;7(5):e362-363.

3. Llitjos JF, Leclerc M, Chochois C, Monsallier JM, Ramakers M, Auvray M, et al. High incidence of venous thromboembolic events in anticoagulated severe COVID-19 patients. J Thromb Haemost 2020 Apr 22. doi: 10.1111/jth.14869 [Epub ahead of print].

4. Middeldorp S, Coppens M, van Haaps TF, Foppen M, Vlaar AP, Müller MCA, et al. Incidence of venous thromboembolism in hospitalized patients with COVID-19. J Thromb Haemost 2020 May 5. doi: 10.1111/jth.14888 [Epub ahead of print].

5. Bikdeli B, Madhavan MV, Jimenez D, Chuich T, Dreyfus I, Driggin E, et al. COVID-19 and thrombotic or thromboembolic disease: implications for prevention, antithrombotic therapy, and follow-up. J Am Coll Cardiol 2020;75(23):2950-2973.

6. Kollias A, Kyriakoulis KG, Dimakakos E, Poulakou G, Stergiou GS, Syrigos K. Thromboembolic risk and anticoagulant therapy in COVID-19 patients: emerging evidence and call for action. Br J Haematol 2020;189(5):846-847.

7. Poggiali E, Bastoni D, loannilli E, Vercelli A, Magnacavallo A. Deep vein thrombosis and pulmonary embolism: two complications of COVID-19 pneumonia? Eur J Case Rep Intern Med 2020;7(5):001646.

8. Levey HR, Segal RL, Bivalacqua TJ. Management of priapism: an update for clinicians. Ther Adv Urol 2014;6(6):230-244.

9. Montague DK, Jarow J, Broderick GA, Dmochowski RR, Heaton JPW, Lue TF, et al. American Urological Association guideline on the management of priapism. $J$ Urol 2003;170(4 Pt 1):1318-1324.

10. Van der Horst C, Stuebinger H, Seif C, Melchior D, Martínez-Portillo FJ, Juenemann KP. Priapism: etiology, pathophysiology and management. Int Braz J Urol 2003;29(5):391400 